\title{
A NOÇÃO DE UMA CULTURA DA JUVENTUDE ROMÂNTICA EM WALTER BENJAMIN
}

\section{Priscilla Stuart da Silva ${ }^{1}$}

Resumo: Neste artigo apresenta-se a noção de uma cultura da juventude romântica em Walter Benjamin e as ideias relacionadas a ela, a saber: crítica, espírito e formação. Analisa-se a crítica do autor quanto ao conceito de experiência, relacionada ao adulto/filisteu, e sua proposta para o cultivo da cultura da juventude. Utilizam-se os ensaios Experiência, Sobre o programa da filosofia futura e $A$ vida dos estudantes.

Palavras-chave: juventude, experiência, crítica, filisteu, cultura

Resumen: En este artículo se presenta la noción de una cultura de la juventud romántica en Walter Benjamin y las ideas relacionadas con ella, a saber: la crítica, el espíritu y la formación. Se investiga la crítica del autor sobre el concepto de experiencia, relacionada con el adulto/filisteo, y su propuesta para el cultivo de una cultura de la juventud. Se utilizan los ensayos Experiencia, Sobre el programa de la filosofía venidera y La vida de los estudiantes.

Palabras clave: juventud, experiencia, crítica, filisteo, cultura

Pode-se mesmo afirmar que a juventude é a única ponte legítima entre o mundo burguês e o mundo natural, um estado pré-burguês, do qual deriva todo o romantismo da estudantada e dos artesãos ambulantes; é ela a idade genuinamente romântica.

Thomas Mann (2011, p. 162)

A tensão entre jovens e adultos, que diz respeito à crítica ao conceito de experiência, é parte da obra de juventude de Walter Benjamin, oriunda das discussões realizadas no Movimento de Juventude Alemão (Berliner Freie Studentschaft), do qual era presidente, no ano de 1914. Nesse período, o filósofo escreveu a maior parte dos textos publicados, posteriormente, na revista Der Anfang ( $O$ Princípio). Seus objetivos partiam da concepção de que a sociedade

\footnotetext{
${ }^{1}$ Doutoranda do Programa de Pós-Graduação em Educação, na Linha de Pesquisa Filosofia da Educação - UFSC. Contato: priscillastuart.di@gmail.com
}

SILVA, Priscilla Stuart da. A noção de uma cultura da juventude romântica em Walter Benjamin. Revista Sul-Americana de Filosofia e Educação. Número 26: maioout./2016, p. 3-24. 
necessitava de uma mudança profunda, sendo que parte dessas ideias havia surgido da leitura prévia da obra de Gustav Wyneken - grande "mentor intelectual" do movimento e do próprio Benjamin - acerca de seus pensamentos sobre sociedade, cultura e educação.

O pensamento de Wynecken exerceu uma influência notável na formação escolar de Benjamin, já que o pedagogo estabeleceu os métodos de aprendizagem - enquanto diretor e professor - na escola em que o filósofo realizou seus estudos iniciais. Benjamin, na citação a seguir, descreve criticamente a escola, um internato em Haubinda, na Turíngia, sobretudo quanto à falta de uma melhor articulação das relações humanas, completamente rendidas a uma massificação em série presente no cotidiano, que afetava, por sua vez, o interior da vida humana:

Quando eu subia as escadas tendo sob os olhos somente botas e pernas e nos ouvidos o arrastar de centenas de pés, creio me lembrar como era, muitas vezes, invadido pela repugnância de me encontrar perfilado nessa massa e como sentia, do mesmo modo que no curso daqueles passeios com minha mãe pela City, que a solidão era a única condição humanamente digna. Isto é completamente natural porque uma tal massa de alunos é das mais informes e indignas e trai sua natureza burguesa já no fato de, como todo agrupamento desta classe, apresentar hoje a forma mais rudimentar de organização que os seus diferentes membros podem dar a suas relações mútuas (BENJAMIN apud MURICY, 2009, p. 38-39).

Por causa dessa relação traumática com a instituição, Benjamin criticou a massificação nas escolas, uma vez que, para ele, todo o ímpeto para mudança, força, audácia e espírito de transformação da sociedade estava presente nos jovens, que têm o espírito leve, que olham para a frente, para o futuro que se abre. O ideal de mudança social estaria presente na juventude, e não nos adultos, os filisteus da cultura, que dizem "não" para "o meio-dia da vida" ${ }^{2}$. Desta forma, as esperanças estão sedimentadas plenamente nos jovens, uma vez que "a juventude

\footnotetext{
${ }^{2}$ Cf. "Preparar o momento da mais elevada autorreflexão da humanidade, um grande meio-dia quando ela olha para trás e para além de si, quando ela se desprenda do domínio do acaso e dos sacerdotes, e pela primeira vez e COMO UM TODO ponha a pergunta do por quê? Do para quê?" (NIEMEYER, 2014, p. 415).
} 
é o elemento não corrompido da sociedade, [pois] seria o motor de transformações culturais capazes de mudar esta sociedade, de acelerar a marcha do espírito" (MURICY, 2009, p. 39).

A escola também é tema de aversão e repressão em outros escritos de Benjamin, incluindo o ensaio Infância berlinense: 1900, e especificamente, o aforismo Atrasado, no qual ele relata a percepção de uma criança reprimida pela indisciplina. O destaque à escola ocorre desde o trauma inicial mostrado pela desordem do aluno, pois, longe de qualquer alusão à sociabilidade como um momento especial da escolarização, a descrição remete a uma lembrança escolar traumática:

O relógio no pátio da escola parecia estar danificado por culpa minha. Marcava a hora 'atrasado'. E ao corredor chegava, vindo das salas de aula por onde eu passava, o murmúrio das misteriosas conversações. Do lado de lá das portas, professores e alunos eram amigos. Ou então ficava tudo em silêncio, como se esperassem alguém. Imperceptivelmente, levei a mão à maçaneta da porta. $\mathrm{O}$ sol banhava de luz o ponto onde me encontrava. E eu, para entrar, profanei o meu dia a nascer. Ninguém parecia conhecer-me, nem mesmo ver-me. Tal como o diabo ficou com a sombra de Peter Schlemihl, também o professor reteve o meu nome no começo da aula. Eu já não ia ser chamado. Trabalhei com os outros em silêncio até ao toque da campainha. Mas não havia nisso nada de reconfortante (BENJAMIN apud MURICY, 2009, p. 44).

Por divergir substancialmente do movimento de juventude de sua época, Benjamin decide romper com seu mestre e interlocutor estudantil Wyneken, por seu apoio à Primeira Guerra Mundial. Barrento descreve o discurso de rompimento do berlinense, ocorrido em março de 1915:

Peço-lhe que veja nestas linhas, com as quais me desligo de si totalmente e sem reservas, como uma última prova de fidelidade, $e$ apenas isso. [...] Este tempo não tem uma única forma que nos permita ficar em silêncio [...] Consigo aprendemos que também o espírito, em si mesmo e de forma incondicional, é capaz de ligar seres humanos vivos, que a pessoa está acima das questões pessoais [...] O senhor 
sacrificou a juventude a um Estado que lhe retirou tudo. Mas a juventude pertence apenas aos idealistas que a amam, $e$ nela amam acima de tudo a ideia... (BENJAMIN apud BARRENTO, 2013, p. 21).

Apesar de romper com o movimento e negar ideais contrários aos seus, o tema da experiência continuará presente no pensamento de Benjamin, tornando-se uma chave de leitura central para o entendimento de seus escritos. Por isso, tornase importante frisar a permanência da concepção, na obra do autor, de uma crítica à cultura e às formas de alienação social presentes na sociedade europeia. Ou seja, uma característica relevante dessa concepção de experiência, para o filósofo, é a de que sua abordagem parte sempre da concretude, da realidade e das vicissitudes presentes em seu espaço social.

Voltando aos textos da juventude, pensar a experiência em Benjamin é, antes de tudo, remeter a esse período, aos seus primeiros escritos, e logo, a ensaios como Experiência - escrito em 1913, de acentuada tendência romântica. Ele tinha a necessidade de denunciar o preconceito contra o espírito juvenil, seu potencial e força revolucionária. Tendo sido formado pelo movimento da juventude alemã, sua linguagem é a de um combatente - "travamos nossa luta por responsabilidade..." - que valoriza as palavras de ordem, para a consequente tomada de ações, contra os clichês do discurso do adulto "experiente". Nesse momento, Benjamin sequer vislumbrava ainda a distinção, que mais tarde travaria, entre experiência (Erfahrung) e vivência (Erlebnis), ou então, sua crítica ao conceito de Kant: um conceito de experiência a partir de uma filosofia do futuro.

No entanto, por volta de 1913, sua concepção de experiência se relacionava, sobretudo, ao seu conceito de vivência (Erlebnis), desenvolvido posteriormente. A experiência, nesse período de juventude, é entendida como um contraponto ao que é novo, vinculada, estritamente, a uma imediaticidade dos acontecimentos, sem aparentar qualquer novidade, por pura repetição.

Seria possível especular aqui que, antes de qualquer relação com a vivência empobrecida pelas ruínas do que restou da guerra, a experiência, nesse homônimo ensaio da juventude, faz uma crítica vivaz à estagnação das tradições e dos povos, 
a esse grande abismo que se cria entre uma geração e sua sucessora, à falta de diálogo e comunicação entre ambas. Logo, a grande dificuldade $e$ as barreiras estabelecidas no espírito humano residiriam na conciliação entre a tradição e o que está nascendo, isto é, a novidade, o futuro.

No referido ensaio, Benjamin acreditava na necessidade de se "combater" os adultos a fim de fazer um elogio aos anos de virilidade e ousadia do jovem. Para tanto, efetuou uma separação radical entre os adultos (filisteus) e a juventude. A experiência (que, no ensaio, aparece entre aspas e como uma forma de alusão à "experiência" do adulto) é associada à brutalidade, à vulgaridade da vida e à falta de sentido para a existência, além de ser entendida como o lugar da aquisição de conhecimento na realização de cada ato humano. Senso assim, nada encorajaria a ação, a atitude, sem previamente saber as consequências que dela surgiriam. A experiência seria o elemento máximo da tábua de valores humanos, determinada, então, pelos filisteus, embora empobrecida de vínculo real com a vida e o espírito de ousadia. Aos jovens sobraria audácia, ímpeto; valores que remetem ao novo, a um futuro que ultrapassa qualquer concepção de experiência estagnada no tempo e em prescrições determinadas. Deste modo, a experiência é, invariavelmente, determinada pelo passado, e por aquilo que é bom, belo, verdadeiro. O espírito de vida não é compatível com a experiência, pensa Benjamin, como um jovem que era. Contudo, espírito e vida não são privilégios apenas dos jovens, pois os adultos os têm em virtude de sua própria experiência, que "é carente de sentido e espírito apenas para aquele já desprovido de espírito" (BENJAMIN, 2009b, p. 23).

Diante disso, a ideia de juventude, nesse ensaio, liga-se antes a um espírito da juventude do que a uma idade específica, determinada cronologicamente.

É oportuno ressaltar também o termo filisteu, utilizado por Benjamin, e o porquê de seu uso no contexto atual. A utilização da palavra vai ao encontro da acepção fornecida por Goethe para nomear o burguês, mas também segue a definição dada por Nietzsche, de que a figura do filisteu se contrapõe ao homem de espírito. Contudo, antes de Nietzsche, o termo já havia aparecido entre os românticos, que o definiam no contexto do ambiente estudantil, como nos afirma Safranski: 
Os românticos denominam como filisteu todo aquele que se dedica completamente à utilidade. A expressão 'filisteu' vem da gíria estudantil e denominava com desdém os não estudantes ou os estudantes que viviam uma vida burguesa normal, sem liberdades estudantis. Para os românticos, o 'filisteu' se torna o símbolo do homem normal por excelência, dos quais querem se distinguir. O filisteu não é todo aquele que gosta do normal, regulamentado - isto o romântico fará também por vezes -, mas aquele que desacredita aquilo que é maravilhoso, cheio de segredo, e o tenta rebaixar a parâmetros normais. O filisteu é uma pessoa rancorosa, que toma por normal o que é excepcional e tenta diminuir o que é sublime. Trata-se pois de pessoas que se proíbem o espanto e a admiração (SAFRANSKI, 2010, p. 182).

Assim, ao beber dessa mesma fonte romântica, o filisteu, em Benjamin, designa um indivíduo mesquinho, preocupado com seu conforto burguês, distanciado da cultura de gênio, de artista, que negaria uma perspectiva de utopia apaixonada, de renovação da realidade (MURICY, 2009, p. 42-43). Logo, o filisteu é pensado como contraponto ao espírito do jovem, que alarga, que expande, pois sua ousadia move-o em direção a uma maior abertura para o mundo, ao que é novo. A experiência do adulto, consequentemente, identificado com esse filisteísmo, conserva-o, mantendo-o fixo a padrões de comportamento, fiel a tradição do que já viveu e ao conteúdo já existente dessa vivência.

Ao final do ensaio, Benjamin parece querer conciliar-se com o conceito de experiência, remetendo o problema ao filisteu, que já não vê mais sentido e valor em sua vida. Em nota, M.V. Mazzari, o tradutor do ensaio para o português (BENJAMIN, 2009b, p. 21; nota de rodapé número 1) informa acerca da mudança de perspectivas que fez com que o filósofo retomasse esse conceito anos depois:

Numa nota escrita provavelmente em 1929, Benjamin lança um olhar retrospectivo a este texto ['Experiência] de 1913: 'Num de meus primeiros ensaios mobilizei todas as forças rebeldes da juventude contra a palavra 'experiência'. E eis que agora essa palavra tornou-se um elemento de sustentação em muitas de minhas coisas. Apesar disso, permaneci fiel a mim mesmo. Pois o meu ataque cindiu a 
palavra sem a aniquilar. $\mathrm{O}$ ataque penetrou até o âmbito da coisa' (BENJAMIN, 2009b, p. 21; nota de rodapé número $1)$.

O conceito de experiência em Benjamin, desde a sua primeira abordagem, precisa ser pensado pela perspectiva da imagem, de uma constelação, contrário a uma perspectiva de evolução do conceito. A ideia de uma "utopia romântica", como chamará Michael Löwy (2012, p. 125-139) permanecerá também em seus escritos da maturidade como uma busca, uma procura pela experiência perdida na modernidade, como nos ensaios Experiência e pobreza e $O$ narrador consideraçôes sobre a obra de Nikolai Leskov. Segundo Valéry - citado por Benjamin -, a experiência não é mais possível porque "o homem de hoje não cultiva o que não pode ser abreviado" (VALÉRY apud BENJAMIN, 2010e, p. 206)frase que condensa, de alguma maneira, essa concepção na contemporaneidade acerca do enfraquecimento da experiência.

Voltando ao ensaio de 1913, segundo Pereira (2009, p. 243), Benjamin havia pensado sobre a experiência não como uma categoria, mas como uma concepção individual relacionada àquele contexto, pois não vislumbrava uma crítica à modernidade. Ou seja, pensou nela como uma crítica ao combate e à ação revolucionária, não como uma teoria crítica da cultura propriamente dita. De todo modo, é possível encontrar ressonâncias nos escritos posteriores.

\section{Ecos de Nietzsche e a favor de uma juventude crítica: o espírito livre contra o espírito utilitário}

No ensaio $A$ vida dos estudantes é possível encontrar uma correspondência desse pensamento combatente, pois nele se percebe um jogo com a conhecida imagem do mosaico, da micro e da macro histórias. Ao afirmar que os estudantes, a rotina no meio intelectual acadêmico e toda a perspectiva que funda na juventude o futuro de ações revolucionárias são como "símile[s], como reflexo[s] de um momento mais elevado e metafísico da História" (BENJAMIN, 2009a, p. 31), parece haver aqui uma representação ou um: 
Desenho mítico do que será a sua concepção da História das teses de 1940: a rejeição da noção de progresso e da concepção de tempo linear, evolutivo e infinito, a visão descontínua da história, concebida como recortada em imagens - imagens utópicas - essas cenas paralisadas $e$ enigmáticas, carregadas de significação, a que somente o olhar do presente decifraria e devolveria o movimento, transformando-as em imagens dialéticas (MURICY, 2009, p. $35)$.

Desta forma, ao início do texto, o filósofo mostra qual é a tarefa histórica do presente. Por conseguinte, a vida dos estudantes mostra-se como uma representação de um momento histórico que clama por mudanças.

Diante dessa tarefa, percebe-se que os desafios que os jovens necessitam enfrentar referem-se às dificuldades encontradas no interior da instituição acadêmica, crítica já presente no ensaio Experiência, quando Benjamin alude aos "estudantes livres em oposição ao poder reacionário das corporações". Contudo, em direção oposta, faz também uma crítica às próprias organizações estudantis que integrou, pois havia testemunhado, naquele período, uma espécie de "submissão acrítica e inerte a esse estado" como "um traço essencial na vida dos estudantes" (BENJAMIN, 2009a, p. 34). De forma similar, assim como acontece com os jovens acadêmicos, a cultura também está em perigo no interior das próprias corporações políticas, como a universidade, pois a ordem geral que predomina no presente é a conversão ou aniquilamento do espírito criador transformado em espírito puramente profissional e utilitário.

Encontramos uma crítica, correlata à de Benjamin, aos estabelecimentos de ensino alemães, na conferência inacabada, e publicada postumamente, de Nietzsche: Sobre o futuro de nossos estabelecimentos de ensino:

Pode-se quase tentar aqui ler positivamente, no limite, estas conferências de Nietzsche como testemunhas de uma época que conheceu uma especialização cada vez mais forte das formas de conhecimento $e$, em consequência, do valor formativo da filosofia e da cultura e, com isso, ameaçava o status da formação geral em prol de uma educação profissional - sujeita a uma ponderação de utilidade - e com 
a consequência (apontada por Nietzsche) de que não se deveria mais falar de 'estabelecimentos de ensino' mas de "repartição" ou "ganha pão" (NIEMEYER, 2014, p. 70).

Nietzsche foi um pensador importante para Benjamin em seus primeiros escritos, embora haja muitas referências a ele em sua última obra intitulada Sobre o conceito de história ${ }^{3}$. Em $A$ vida dos estudantes, o filósofo prussiano critica também as organizações acadêmicas e os profissionais que atuam no interior dessas instituições, o que aproxima os dois pensadores. Nietzsche se refere aos profissionais da educação que "formam" os jovens a serviço de uma cultura oficial, utilitária, pragmática da sociedade, desviando-os de uma educação que deveria educar para gerar espíritos livres. Os profissionais acadêmicos, atesta, estariam à mercê de uma cultura de especialistas "que obedece convenientemente a uma certa divisão do trabalho. [...] A cultura não pode se reproduzir e crescer quando a educação está orientada para uma profissão, uma carreira, uma função, um cargo, quando é movida pelo 'espírito utilitário'” (SOBRINHO, 2007, p. 11). A universidade, quando fornece autonomia e individualidade para os estudantes obedecendo aos seus princípios de liberdade acadêmica -, promoveria, na verdade, mediocridade e falsa erudição.

Certamente os objetivos de Benjamin e Nietzsche são distintos: enquanto o primeiro pretendia uma educação para a ação revolucionária do pensamento, a fim de interromper o curso desastroso da história, o segundo acreditava em uma cultura e civilização capazes de criar homens livres, homens de exceção. Já o ponto em comum entre os filósofos residia no fato de que, com espírito livre, individual ou coletivo, a sociedade seria capaz de promover autonomia no espírito humano. Nietzsche, porém, sustinha um pensamento aristocrático, pois, embora acreditasse na capacidade individual e no cultivo de si, não cria que todos fossem capazes de promover a autossuperação. Contudo, assim como Benjamin, acreditava que as instituições de ensino confundiam espírito livre com espírito utilitário.

\footnotetext{
${ }^{3}$ Cf. No livro de Ernani Chaves - fruto de sua tese - encontra-se um dedicado estudo sobre os dois filósofos: CHAVES, Ernani. No limiar do moderno: estudos sobre Friedrich Nietzsche e Walter Benjamin. Belém: Paka-Tatu, 2003.
} 
Diante dessa reflexão, percebe-se que a grande pretensão do berlinense nesse período e nesses escritos - é justamente a formação do gênio, do indivíduo solitário, assim como queria Nietzsche. No trecho abaixo, a diferenciação entre sociedade (Gesellschaft) e comunidade (Gemeinschaft) aproxima novamente os filósofos alemães, de modo contundente:

A ideia de uma comunidade de jovens é assentada sobre a convicção de que a juventude é uma idade metafísica em que se articulam solidão e empenho na realização de um ideal. Esta disposição funda uma comunidade de solitários "amigos estrangeiros" - de forma muito diversa da que sustenta a sociabilidade, a camaradagem fraterna feita por identificações afetivas. $\mathrm{O}$ ideal em torno do qual se une a comunidade é o que se poderia chamar de uma espera atenta, uma receptividade às manifestações espirituais da época. Nesta atenção voltada para fora do círculo, solitários, esses jovens evitariam a formação de uma sociedade de interesses privados. Esta postura ética é básica para a metafísica da juventude que Benjamin busca elaborar como alternativa crítica para a cultura. Para Adorno, ela permanecerá em sua obra, expressando o desejo de integrar o gênio, o indivíduo solitário, à comunidade, sem que a sua capacidade crítica seja comprometida pelos interesses de uma associação (MURICY, 2009, p. 41).

Um pouco antes desse trecho, a autora percebe a aproximação com Nietzsche quanto ao tema da crítica da cultura. Benjamin, nesses ensaios de juventude, mantém-se distante frente a qualquer tipo de concentração ideológica, partidária, política e panfletária. Contrário a isso, sua percepção é da "espera" filosófica, do cultivo, lento e demorado do espírito pela atuação da crítica filosófica.

A crítica como instrumento de posicionamento do jovem frente à sua realidade é outro elemento romântico presente no pensamento de Benjamin. Sua tese de doutorado acerca do conceito de crítica de arte na época do romantismo alemão, de 1919, já mostra a importância que esse conceito exercia em seu pensamento. O filósofo irá pensá-lo e retomá-lo como um gênero discursivo notável na Alemanha, definindo-o como um "medium-de-reflexão" (Reflexionsmedium). No contexto mencionado, da ação revolucionária dos jovens, 
a crítica já possui esse caráter revolucionário - agora no contexto da crítica política, e não só estética -, pois "também o crítico é escritor: ele escreve crítica. Essa valorização da dimensão da materialidade da escrita na forma de expressão é que dá o caráter poético da crítica, cujo exercício, então, está menos distante da obra sobre a qual fala do que, em geral, supomos" (DUARTE, 2011, p. 98).

Conforme se evidencia, o berlinense criticou a juventude universitária de sua época, no que diz respeito à ação, militância e combates da ordem estabelecida pelos meios acadêmicos. Ele acreditava, ao contrário, na dimensão da vida do "espírito" e da cultura, embora fosse a favor, ao mesmo tempo, da crítica como atividade e ação revolucionárias. Sua defesa não elimina a ação e o ímpeto de mudança, mas seu "material de ação" encontra-se no espírito filosófico, na educação e na formação pela arte e pela existência intelectual, em suma, pela crítica. Reiterando, a crítica é a sua grande arma na luta enquanto jovem revolucionário, pois "o lugar da crítica é o modo da experiência histórica, entendida como atividade do espírito" (MURICY, 2009, p.43).

\section{Princípio moral $e$ filosofia do futuro: a importância de Kant}

Os escritos da juventude de Benjamin se pautam, inteiramente, em uma concepção de filosofia do futuro, baseada em um princípio e na regulação de uma experiência que dê conta da totalidade da vida. No ensaio $O$ ensino de moral, o filósofo menciona a tarefa pedagógica ou a finalidade de qualquer educação ética, desde um princípio, o que Novalis chama de "um ideal a priori, uma necessidade para existir" (NOVALIS apud BENJAMIN, 2010a, p. 242), em busca de uma unidade na existência.

Nele se delineia o problema de as lições éticas substituírem a própria experiência da vida, mostrando que, por meio da comunidade, esses sentimentos éticos são possíveis de serem apreendidos. Benjamin ressalta a importância do desenvolvimento da atitude ou atividade ética como algo indispensável, como uma postura determinante para aquilo que ele chama de "princípio da comunidade estudantil livre" da liberdade. Outro fator relevante na comunidade de jovens é o caráter religioso enquanto elemento imperativo para encontrar o conteúdo ético- 
comunitário no interior dessa congregação. Esse caráter religioso transcende os limites do visível, do sensível e do institucional, reino que não diz respeito às normas específicas de uma religião qualquer, mas a um sentimento de religiosidade compreendido como um sentimento metafísico de comunidade, algo que, como dito, perpassa os limites do experienciável, isto é, aquilo que só é passível de se compreender e alcançar na comunidade da juventude. (BENJAMIN, 2009c, p. 14$15)$.

Como se pode perceber a partir dessas reflexões, há uma crítica à formação puramente institucional do jovem, pois "os fundamentos racionalistas $e$ psicológicos" da escola e da universidade só podem atingir aquilo que está "prescrito, mas jamais a atitude ética". O filósofo ainda defende que "o ensino de moral combate o elemento periférico, carente de convicção em nosso conhecimento; combate o isolamento intelectual da formação escolar" (BENJAMIN, 2009c, p. 18-19).

Desta forma, grande parte desse pensamento foi extraída de leituras de Kant, pois, como afirma Muricy (2009, p.66),

Kant foi para Benjamin, neste período juvenil, a promessa de um sistema. Sua leitura de Kant, no entanto, é muito especial: mais do que fidelidade à letra kantiana, trata-se para Benjamin de encontrar no sistema crítico um abrigo para a sua concepção de filosofia como doutrina (die Lehre). Pretensão bem complexa à luz do conteúdo nitidamente antidogmático do criticismo. Por volta de 1917, o pensamento de Kant aparece para Benjamin como o marco a partir do qual se define a tarefa da filosofia.

Conforme salientado, a influência de Kant foi decisiva, sobretudo quanto à importante teoria da experiência benjaminiana. A experiência para o filósofo de Königsberg foi o ponto de partida para fundar uma concepção que abarcasse a experiência da realidade, uma teoria que permitisse auxiliar os níveis e os limites daquilo que pode ser conhecido. Benjamin pensava em uma caracterização da experiência pautada pelos elementos de profundidade e continuidade contra uma fundamentação baseada na física newtoniana, determinada e apriorística. 
Contudo, argumentava também que nenhuma filosofia, até então, havia construído suas fundações sobre uma base teórica da experiência tão firme, sólida, sistemática e histórica como a de Kant. Sua justificação do conhecimento fundou as bases para um sistema de relação tricotômico: natureza, liberdade e experiência, superando, assim, as diferenças entre as três instâncias e fundando-as sobre parâmetros de uma metafísica entendida como ciência empírica. Ao partir da caracterização de continuidade, pensou acerca de um conceito de experiência no qual o conhecimento serviria como doutrina (die Lehre). A filosofia de Kant, para o jovem Benjamin, seria a porta de entrada para todo e qualquer pensamento que se autodenominasse filosófico.

Benjamin reconheceu dois grandes filósofos na tentativa de justificar a filosofia pelos parâmetros do conhecimento em seus ensaios da juventude, são eles: Platão e Kant. O último teve por mérito sistematizar e superar níveis como liberdade e natureza, embora uma filosofia que pense uma justificação para tudo, da ordem do vindouro, necessite abarcar tudo aquilo relacionado à ordem da experiência, incluindo a história, a teologia, etc. Logo, somente uma filosofia que se baseie em uma formulação de continuidade, e não mais de determinação (como da matemática), pode buscar essa fundamentação.

Nesse momento (nos primeiros ensaios, quando ainda não separava Erfahrung de Erlebnis) teve início o grande rompimento de Benjamin com Kant, pois, enquanto o primeiro defendia a noção da experiência como continuidade na história - conceito aberto às experiências do cotidiano, "experiências absolutas" -, o segundo, por sua vez, defendia uma experiência em que o conteúdo se limitava às determinações e regras da matemática e da física.

No entanto, para Benjamin, ainda assim, todo e qualquer conhecimento que se defenda como filosófico deverá passar, necessariamente, pelo sistema kantiano. O filósofo de Königsberg separava radicalmente o conhecimento da experiência da própria experiência. Sua tentativa de fundar uma metafísica (que, para ele, era sinônimo de ciência especulativa, com profunda influência da física newtoniana) na razão pura, não permitia qualquer interferência que fosse da 
ordem da experiência, separando, assim, conhecimento e experiência. Pelas palavras de Benjamin:

De esta manera se evito desde un principio un centro teórico uniforme de conocimiento cuya, en exceso poderosa fuerza de gravedad podría arrastrar toda experiencia en sí, de otra parte, fue comprensible de suyo la necesidad de lograr producir algo para un fondo de posibilidad a posteriori de la experiencia, es decir, cuando tampoco el contexto haya roto la continuidad de conocimiento y experiencia. ${ }^{4}$

Ao desvincular o conhecimento da experiência, esse "esclarecimento da razão", do qual Kant era herdeiro, ocultava as "potências espirituais capazes de fornecer à experiência um grande conteúdo" (MURICY, 2009, p. 75). De todo modo, Benjamin realizou aquilo que indicava em seu programa da filosofia futura, ao fundamentar sua teoria - poderíamos imaginar o desenho de um mosaico para ilustrar - mediante uma noção de experiência superior que abarcasse a história, a literatura, a linguagem e os domínios da cultura ainda por conhecer.

Nesse texto, Benjamin esboça a compreensão de uma filosofia futura sedimentada em solo kantiano, mas cujo projeto logo abandonará. Todavia, já delineia, ao mesmo tempo, seus temas limiares entre "la temporalidad relampagueante de lo fugaz, lo transitorio, lo que tiende a no permanecer, y el desarrollo de una teoría del conocimiento cuya condición sería precisamente la de lo atemporal" (GALENDE, 2009, p. 37-38). O projeto kantiano não conseguiu pensar em um conceito superior ao de experiência, dando conta - somente - da justificação do conhecimento. O autor explica essa "inabilidade" kantiana ao propor, como explicação, a redução e o empobrecimento sistemático da experiência na esfera moderna.

De alguna manera la mayoría de edad del hombre ilustrado se expresa, dicho dialécticamente, en un empobrecimento de su experiencia, tal como ocurre en el tránsito que va del niño o el monstro al Yo fingidamente soberano y adulto. Es como

\footnotetext{
${ }^{4}$ BENJAMIN, Walter. Sobre la percepción. Trad. Omar Rosas. Departamento de Filosofía/Universidade Nacional de Colômbia, p. 1. Disponível em: http://goo.gl/aYDV8a
} 
si el hombre perdiera en experiencia aquello que gana haciendo uso práctico de su razón (GALENDE, 2009, p. 3839).

Retomando a crítica de Benjamin a Kant, vê-se que, no primeiro, não é possível separar sujeito e objeto como duas instâncias diversas, como também uma consciência empírica separada da experiência. Não é possível identificar um conteúdo objetivo da experiência, tampouco aquela surgida de uma subjetividade. A experiência se dá posterior ao sujeito, na ausência dele. "Sujeto, en realidad, es el nombre para algo que siempre llega tarde a la experiencia, así como es experiencia el nombre para aquello que irrumpe en el páramo del ser, antes o después de que existencia y existente se anuden en el lecho de la subjetividade" (GALENDE, 2009, p. 40).

Em Kant, o problema da experiência é levado a seu extremo, isto é, o da impossibilidade do sujeito experienciar-se, tendo em vista que ele está sempre fadado a uma representação de si mesmo, que jamais obtém uma experiência como uma realidade de si e do mundo. Contudo, somente sua filosofia foi capaz de alcançar a dimensão de uma experiência fundadora de outras instâncias da realidade humana.

\section{Metafísica da juventude ou uma nova cultura da juventude}

Antes que lutar por uma concepção, teoria ou noção de conhecimento, Benjamin não reivindica ao jovem valores já existentes, como o bem ou o mal, mas luta pela própria possibilidade de valores que, em seu diagnóstico do presente, são impossibilitados pela cultura, uma vez que esta vive imersa em uma crise. Desta forma, a liberdade, o ensino da moral, a religiosidade como valor histórico e metafísico não são propriamente programas no sentido kantiano, mas significam uma mentalidade que deve ser protegida e cultivada por essa nova cultura da juventude emergente.

Apoiado pelas formulações de Nietzsche, Benjamin argumenta que os jovens necessitam despertar para uma iluminação da consciência, isto é, despertar 
para o sentido histórico de suas existências. Em seu ensaio Pensamientos sobre el Festival de Gerhart Hauptmann, ele critica o sentido histórico do presente direcionado para o condicionado, para aquilo que já está dado e estabelecido, e não para o incondicionado, aquilo que está por vir e que é mostrado como tarefa (BENJAMIN, 2010f, p. 57).

O filósofo chama essa juventude - que tem como tarefa despertar o espírito e libertá-lo do condicionamento histórico - de "verdadeira juventude romântica", pois somente ela entenderá que o romantismo é uma vontade operante, de modo que, com essa mentalidade, as escolas darão lugar a um novo tipo de ensino (BENJAMIN, 2010g, p. 47).

Em um de seus primeiros textos, $A$ bela adormecida, publicado com o pseudônimo "Ardor", na revista juvenil Der Anfang, Benjamin afirma que a juventude ainda não tem conhecimento de que o príncipe que a libertará está próximo. Ele evoca a imagem do Fausto, de Goethe, que possibilita entender o espírito do jovem, pois Fausto é o representante mais universal da juventude; nele está contida a concepção de que uma pessoa é jovem na medida em que não tenha realizado seu ideal de vida completamente. De acordo com o berlinense, o envelhecimento consiste em enxergar a medida da perfeição no dado, no pronto, no acabado. Talvez essa seja a maior lição que o espírito da juventude possa fornecer.

Outra figura clássica da literatura menciona por Benjamin é Hamlet, personagem que representa o dever do jovem e de sua autoconsciência, como se pode perceber nesta passagem:

El corazón de Hamlet se encuentra amargado. Su tío le parece un asesino, y su madre le parece una incestuosa. ¿Qué sentimiento es fruto de este conocimiento? El mundo le asquea, pero Hamlet no se aparta de él a la manera de un misántropo, sino que tiene un sentimiento de misión: Hamlet ha venido al mundo para ponerlos en orden. ¿A quién podríamos aplicar estas palavras mejor que a la juventud de nuestros días? Pese a todo lo que se dice sobre la juventud, el amor y la primavera, en todo joven que piensa encontramos el germen del pesimismo. Y este germen tiene el doble de fuerza en nuestros tiempos. Pues, ¿cómo puede 
un joven (en especial el de la gran ciudad) afrontar los problemas más profundos, la miseria de la sociedad, sin sucumbir al menos, ahí sólo puede y debe ayudarnos la consciencia: por malo que sea el mundo, tú has nacido para enderezarlo. Esto no es arrogancia, sino sólo consciencia del deber (BENJAMIN, 2010b, p. 10).

Esse dever, atesta Benjamin (2010d, p.63-65), inclui discutir uma nova pedagogia filosófica como, por exemplo, a relação entre mestre e aluno, a própria caracterização da crítica e questões relacionadas à reforma educacional alemã, ou ainda, questões presentes na cultura como um todo.

Por isso, conforme salientado ao início deste artigo, a figura do jovem está ligada a uma ideia maior, a um tema geral de educação, uma vez que Benjamin compreende juventude como uma espécie de bússola da vida, momento em que as sementes e a projeção de um futuro estão unidas, em que a crítica é reconhecida como horizonte e atitude de mudança no contexto educacional e onde permanece o espaço no qual é possível pensar na formação humana mediante outra perspectiva, isto é, da vida do espírito.

É possível ainda pensar na juventude como categoria não corrompida da sociedade, como motor de transformações culturais capaz de mudar a sociedade, de acelerar a marcha do espírito (MURICY, 2009, p. 41), como um período da vida que ultrapassa até mesmo o âmbito cronológico, conforme o exemplo da figura de Fausto. Benjamin realiza uma espécie de "dobra", transformando o jovem em uma categoria filosófico-pedagógica responsável por transcender uma realidade estática e aprisionada. O filósofo recupera, assim, o indivíduo, inserindoo em uma categoria que transcende os interesses isolados.

Outro elemento que circunda a categoria da juventude em Benjamin é a espera: o jovem como aquele que espera e que está aberto ao novo. Podemos pensá-la também como conceito, como lugar, onde a teologia e o messianismo se fazem presentes, e que evidencia uma noção de um tempo não linear $e$ homogêneo. Para o judaísmo, religião na qual Benjamin foi educado, o futuro é aberto à espera do messias, ao mesmo tempo em que ele é preservado. Faz-se necessário pensar, então, na preparação do tempo da experiência do hoje, já que 
o jovem vive o presente de maneira intensa, efêmera, no tempo do acontecimento iminente, em um diálogo constante e direto com a tradição que o antecedeu, sobretudo, em um movimento e comunidade atuantes no tempo do agora, do presente que urge. "Se alguma vez já pensamos em nós, não em nós como indivíduos, mas em nós como comunidade, como juventude - ou se já lemos a respeito da juventude -, sempre pensamos que ela certamente deve ser romântica”. (BENJAMIN, 2013, p. 53).

\section{Conclusão}

A juventude parece ser um período pré-burguês da sociedade, quando ainda as ideias não enrijeceram, conforme afirma Thomas Mann na epígrafe deste trabalho (MANN, 2011, p. 162). O problema da juventude em Benjamin é redimensionado para uma nova categoria, a de comunidade, como dito. Para Hölderlin, "o homem apenas pode elevar-se sobre a indigência ao recordar o seu destino, ao prezar e poder ser grato pela sua vida a ponto de sentir o nexo recorrente que estabelece com o elemento dentro do qual se move" (HÖLDERLIN, 1994, p. 23-27). Aqui o gênio é formado. Neste sentido, a sociedade é apenas a consolidação de interesses privados de indivíduos isolados. $\mathrm{Na}$ comunidade de jovens existe uma ideia metafísica compartilhada. A sociedade promove uma cultura de massas, mas Benjamin não almeja uma cultura de massas, e sim, uma cultura dos escolhidos.

A formação é o horizonte visado pelo filósofo, e também pelos frankfurtianos, aos quais Benjamin também se associou. Para ele, contudo, novamente próximo dos românticos e de um messianismo filosófico, esse conceito está longe do projeto da modernidade que se apoia, sobretudo, na razão para pensar a formação humana, ou dos próprios frankfurtianos, que queriam fundar outra razão.

Pensando, então, na formação de uma cultura da juventude crítica, é possível pensar, ao mesmo tempo, na transformação radical da sociedade e dessa mesma cultura pela ação da juventude esclarecida. Para isso, Benjamin discute 
incisivamente, em seus primeiros escritos, a proposta de uma reforma escolar conjugada com a noção de espiritualidade, ou seja, uma reforma que tivesse como objetivo a educação do espírito, e não uma pedagogia de reforma tecnicista. Benjamin critica - já na sua época, mas muito atual para os dias de hoje - o engessamento das instituições de ensino alemãs, a institucionalização da educação. Por isso, a educação, diferentemente da concepção corrente, aproxima-se antes de uma existência trágica da vida, de uma experiência real e sagrada. Ele não negava as instituições de ensino, pelo contrário, advogava uma reforma radical dessas instituições e na aproximação com a experiência da vida não institucionalizada.

Deste modo, o filósofo realiza uma crítica contundente ao comportamento dos jovens, pois, de acordo com sua análise, os mesmos têm dificuldade de unir sua profissão com a própria vida, a exemplo dos clássicos: "as questões metafísicas de Platão e Espinosa, dos românticos e de Nietzsche significaria [um] aprofundamento maior da relação entre profissão e vida, evitaria o enrijecimento do estudo em um amontoado de conhecimentos" (BENJAMIN, 2009, p. 41).

Logo, a compreensão de formação e participação coloca no horizonte de atuação a relação entre professor e aluno, já que ambos "devem compreender, primeiramente, que são laboratórios de si próprios e que, por isso, precisam fazer experiências consigo mesmos para que possam tomar a qualidade de vida como o principal em sua 'formação', isto é, uma educação para a vida" (SOUSA, 2009, p. 73).

Por conseguinte, busca-se uma reforma escolar, uma outra pedagogia, que amplie o sentido do que é ser humano, tomando a juventude como um movimento de ancoragem para a mudança. A escola é o lugar que favorece visualizar os problemas culturais de um período histórico, já que é possível perceber a difusão dos valores de uma sociedade. Desta forma, a representatividade da cultura e da escola, e também das instituições de ensino, encontra-se no jovem, no movimento da juventude (Jugendbewegung). Como afirma Benjamin, "juventud, escuela renovada, cultura: éste es el circulus egregius [círculo excelente] que hemos de recorrer una y outra vez en todas direcciones" (2010c, p. 16). 
A filosofia tem um papel primordial para o filósofo: sob sua forma, a comunidade dos homens criados eleva todo estudo à universalidade e longe de toda particularização do estudo especializado. Isso significaria um maior aprofundamento da relação entre profissão e vida, evitando o enrijecimento do estudo em um amontoado de conhecimento, uma vez que "la falta de reflexión es un pecado. Aquí se encuentra el baluarte de la pobreza intelectual" (BENJAMIN, 1993, p. 108). Ou então, conforme coloca Sousa "o conhecimento opera como instrumento de poder e para se conhecer é preciso, muitas vezes, ter a coragem de se perder para poder se encontrar. Eis, também, em que consiste uma boa prática educacional" (2009, p. 81).

Desta forma, o objetivo deste artigo foi verificar como Benjamin - filósofo que dialoga diretamente com o período moderno de nossa história - situou os principais problemas da formação e da educação de sua época, e como isso permitiu que ele realizasse um prognóstico que contribui com a sociedade contemporânea, ao propor uma cultura da juventude romântica.

\section{REFERÊNCIAS}

BARRENTO, João. Limiares: sobre Walter Benjamin. Florianópolis: EDUFSC, 2013, p. 21.

BENJAMIN, Walter. A vida dos estudantes. In: Escritos sobre a criança, o brinquedo e a educação. Trad. Marcus Vinicius Mazzari. São Paulo: Duas Cidades/Ed. 34, 2009a, p. 31-47.

. El idiota de Dostoievski. In: In: Obras. Libro II. Vol.1. Trad. Jorge Navarro Pérez. Madrid: Abada Editores, 2010a, p. 242.

. Experiência. In: Escritos sobre a criança, o brinquedo e a educação. Trad. Marcus Vinicius Mazzari. São Paulo: Duas Cidades/Ed. 34, 2009b, p. 21-25.

. La bella durmiente. In: Obras. Libro II. Vol.1. Trad. Jorge Navarro Pérez. Madrid: Abada Editores, 2010b, p. 9-13.

. La reforma escolar, un movimiento cultura. In: Obras. Libro II. Vol.1. Trad. Jorge Navarro Pérez. Madrid: Abada Editores, 2010c, p. 13-16. 
- Metas e caminos de los grupos pedagógicos estudiantiles. In: Obras. Libro II. Vol.1. Trad. Jorge Navarro Pérez. Madrid: Abada Editores, 2010d, p. 6167.

. O ensino de moral. In: Escritos sobre a criança, o brinquedo e a educação. Trad. Marcus Vinicius Mazzari. São Paulo: Duas Cidades/Ed. 34, 2009c, p. 11-19.

. O narrador. Considerações sobre a obra de Nikolai Leskov. In: Obras escolhidas. Magia e técnica, arte e política. Trad. Sergio Paulo Rouanet. São Paulo: Brasiliense, 2010e, p. 206.

- Pensamientos sobre el Festival de Gerhart Hauptmann. In: Obras. Libro II. Vol.1. Trad. Jorge Navarro Pérez. Madrid: Abada Editores, 2010f, p. 5761.

. Romanticismo: la respuesta del profano. In: Obras. Libro II. Vol.1. Trad. Jorge Navarro Pérez. Madrid: Abada Editores, 2010g, p. 47.

. Romantismo: um discurso não proferido para a juventude escolar. In: O capitalismo como religião. Trad. Nélio Schneider. São Paulo: Boitempo, 2013, p. 53-57.

. Sobre el programa de la filosofía venidera. In: Obras. Libro II. Vol.1. Trad. Jorge Navarro Pérez. Madrid: Abada Editores, 2010h, p. 162-175.

Sobre la percepción. Trad. Omar Rosas. Departamento de Filosofía/Universidade Nacional de Colômbia, p. 1. Disponível em: http://goo.gl/aYDV8a

. Veladas estudiantiles de literatura. In: La metafísica de la juventud. Trad. Ana Lucas. Barcelona: Paidós, 1993, p. 107-112.

D’ANGELO, Martha. Arte, política e educação em Walter Benjamin. São Paulo: Loyola, 2006. 
DUARTE, Pedro. O nascimento da crítica de arte. In: Estio do tempo: romantismo e estética moderna. Rio de Janeiro: Zahar, 2011, p. 85-98.

FRAGOSO, Williard Scorpion P. Notas sobre a verdade, o belo, o bem e a linguagem no jovem Benjamin. Revista Cadernos Walter Benjamin, Ed. UECE, vol. 6, janeiro a julho de 2011. Disponível em: www.gewebe.com.br/cadernos_vol06.htm

GALENDE, Federico. Sobre una filosofia por venir.In: Walter Benjamin y la destrucción. Santiago de Chile: Metales Pesados, 2009, p. 37-48.

HÖLDERLIN, Friedrich. Reflexões. Trad. Marcia de Sá Cavalcante e Antonio Abranches. Rio de Janeiro: Relume-Dumará, 1994, p. 23-27.

LÖWY, M. A utopia romântica de Walter Benjamin. In: Judeus heterodoxos. Trad. Marcio H. de Godoy. São Paulo: Perspectiva, 2012, p. 125-139.

MANN, Thomas. Doutor Fausto. Trad. Herbert Caro. Rio de Janeiro: Nova Fronteira, 2011, p. 162.

MURICY, Katia. A metafísica da juventude. In: Alegorias da dialética: imagem e pensamento em Walter Benjamin. Rio de Janeiro: Nau, 2009, p. 35-83.

NIEMAYER, Christian (Org.). O grande meio-dia. In: Léxico Nietzsche. Trad. André Muniz Garcia, Ernani Chaves, Fernando Barros, Jorge Luiz Visenteiner e William Matiolli. São Paulo: Edições Loyola, 2014, p. 70, p. 415.

NIETZSCHE, F. Sobre o futuro de nossos estabelecimentos de ensino. In: Escritos sobre educação. Trad. Noéli Correia de Melo Sobrinho. Rio de Janeiro: Ed. PUCRio, 2007, p. 41-137.

PEREIRA, Marcelo de Andrade. Juventude, experiência e conhecimento em Walter Benjamin: para um novo saber da educação. Currículo sem Fronteiras, v. 9, n. 2 , p. 242-257, Jul/Dez 2009.

SAFRANSKI, Rüdiger. Romantismo: uma questão alemã. Trad. Rita Rios. São Paulo: Estação Liberdade, 2010, p. 177-190.

SOBRINHO, Noéli Correia de Melo. Apresentação: a pedagogia de Nietzsche. In: NIETZSCHE, F. Escritos sobre educação. São Paulo: Edições Loyola, 2007, p. 739.

SOUSA, Mauro Araujo de. Nietzsche: viver intensamente, tornar-se o que se é. São Paulo: Paulus, 2009, p. 70-82. 